\title{
A Pattern for Eco-park design in Beshghardash landscape
}

\author{
Mojgan Ghorbanzadeh ${ }^{1}$, Seyed Hasan Taghvaei ${ }^{2}$ \\ ${ }^{1}$ Instructor, Department of Architecture, University of Bojnord, Bojnord, Iran \\ ${ }^{2}$ Associate Professor, Department of landscape Architecture, Shahid Beheshti University,Tehran, \\ Iran
}

\begin{abstract}
Nowadays, attention to strengthen environmental problems, effected from increasing population and process of development in countries, one of the major concern of designers is recognition of the suitable conditions of natural environment, and promotion of the environmental quality. This case with focus to present capabilities and uses of biodiversity and domestic is applied. Eco-park is one of the capabilities which have been designed to the following objectives: Protection of environment and environmental technology progress, Promenade and demonstrate, Learning information for public and Displaying unification between nature and human and their mutual relationship for promotion the comprehension of environment.

This paper is about investigation and recognition of capabilities, for creating the suitable situation to change as regional Eco-park. The Case study is named "Beshghardash" that is located in $5^{\text {th }}$ Kilometers Bodjnourd (center of northern Khorasan province). This region has approximately 380 hectares area and located in cold and dry climate, which is one of the attractive tourism centers in this region. This study is based on four principles as the following: Protection principle, Development principle, Principle of responsibility to public welfare in present and future, Adapting with situations principle. Finally pattern of designing the Beshghardash Eco-park following the objectives which are in sustainable environment and can say that Beshghardash Eco-park is a natural environment, which moreover to verify to environmental values can answer the sustainable development, like improving the humans life quality.
\end{abstract}

Keywords: Eco-park, Beshghardash, sustainability, semi arid landscape. 


\section{Introduction}

$\mathrm{E}$ vidence shows that planet Earth is experiencing a so-called environmental crisis. This crisis is characterized by three major themes:

- rapid growth of the human population and its associated economic activity

- The depletion of both non-renewable and renewable resources; and

- Extensive and intensive damage caused to ecosystems and biodiversity [1] and[2] and[3] and[4].

In Such a critical situation and obligations, many scientific and artistic disciplines have new approaches to solving or at least reduce the problems. Nowadays the art and knowledge of architecture and landscape architecture spans across many disciplines and, though landscape design can be a focus, the work of environmentalists, ecologists, land artists and environmental designers is often equally valid. Meanwhile, in some countries like Iran with well-known tradition and culture particularly, built environment and settlements could follow an expression and treasure of its cultural values and beliefs of sustainability.

Therefore, the need for a new vocabulary to express a different philosophy of design and approach is very apparent in the discussions of the sustainable architecture and ecological landscape. One of the best potentials in addition, context for examining of this matter is finding the various and useful functions of Natural potentials such as Eco-parks. Foundation of such places, recreational and environmental, is essential in order to achieve the urban sustainable development and observing the following points is recommended:

"Assigning the goals of any project and making it compatible with economic requirements; activities consistency with each other ; making use of local, social and managerial potentials and possibilities to express recreational, educational function. Eco-parks merely developed through activities which are consistent with environment and renewable industry. It constitutes of relevant environmental technology and services, in particular renewable industries and their products." [5]. Therefore, developing countries authorities and professionals consider protection, reviving and putting local environment potentials into order. In this paper, the typical case study reviews has been accomplished the Beshqardash area located in North-East of Iran, which has plenty of capabilities for turning into an Eco-park. This paper is attempting to introduce Beshqardash area and its: natural potentials, the authors consider the basic principles and objectives of Eco- parks. Meanwhile, research and survey of ecological design approaches, vernacular landscaping and appropriate patterns for designing of an ecological park.

In this process, the relevant literature is substantial and spans an immense range from vernacular research and tacit knowledge of architecture and landscaping references to modern technical and scientific studies. There are some propounded theories in environmental design; relation of human and nature, and ecological paradigms of sustainability has been a referral.

In addition, study and examining three examples of Eco-Park in the world, with adaptation from the mentioned propound views, the principles of Eco- Park designing in the presented semi-arid areas in every stage. The compatible cases with environment has been stated in terms of environmental capabilities and the area's cultural and social characteristics that finally access to a compatible pattern can be effective in maintenance and restoration of the natural potentials and environmental development.

\section{The Environment and Context of Project}

The historical -natural area of Beshqardash which named Beshqardash park today, has been located in $\mathrm{Km} \mathrm{5}$, south- west of Bojnourd ( 
center of province of Northern Khorasan) in north-east of Iran (see Figure 1). The word "Beshqardash" in local language means five brothers. According a historical truth, these brothers had taken refuge in this area from tyranny of Mongol governors and had fought against them. Such natural and historical area includes a running spring, very old trees (more than100 years old), many brooks and streams, and old tomb with a beautiful blue color dome which has view among the old trees branches. This place is surrounded by rock mountains and hills, including a $30 \mathrm{~m}$ high hill on the east with five spring emerging on its foot. The medical experts believe that the water from the spring is beneficial for some medical and healing properties.

It unbelievably benefits from a permanent spring per 10 Kilometers and in fact, no other place has known with such a unique situation in terms of widespread springs in mountain environment. Therefore, the city comprehensive design insisted on Beshghardash project because of its natural potentials: abundant drinking water, suitable morphology, natural and artificial coverage, its availability and near access to Bojnord city either on foot or by car.

\section{Environmental Approaches and “Ecologist Landscape Design"}

During the environmental challenges on the beginning of 20th century, there are major approaches to nature and environmental value that emerged from returning to understanding of vernacular tacit knowledge, and ecological approaches of academies around the world.

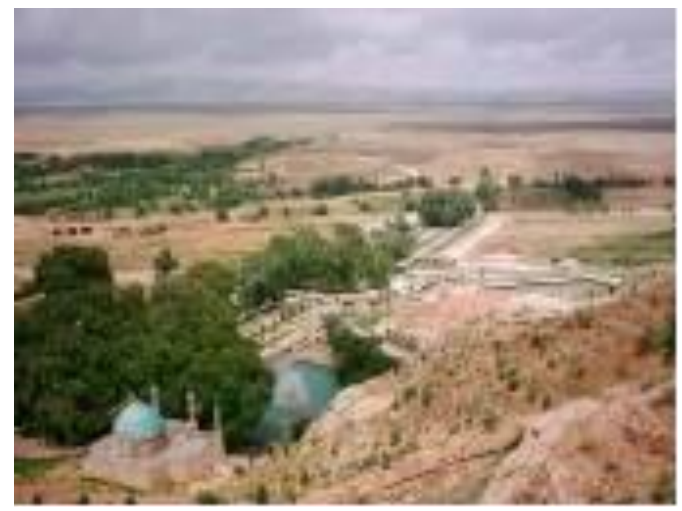

Figur1 1: An overview of Besh Ghardash
These issues had wide range effect on design theories, planning and practice in the middle of last century. In addition, the relevant literature spans an immense range from ancient religious, spiritual and even mythical references to modern technical and scientific studies.

In 1986, Tylor as biology-based scientists has been propounded environmental ethics who has a deep respect for nature. In Tylor's opinion, natural behaviors are suitable pattern for assigning human-nature relation. It is the Structure and operation of earth ecosystem, which clarifies the true relation between human and world's nature. Ecological balance between organisms as well as them and their environment in a healthy ecosystem should be our guidance in formation of a human culture coordinated with nature's system[6].

As a basic environmental-ecological theory and ecocentric thought, Ian McHarg's presentation of an "ecological method" for regional planning and design expresses something of aesthetic motivation underlying the method during forty years. The book of Design with Nature (1996) by McHarg, had intensive effect on planning and design theories and methods.

"While McHarg advocated his theory and, fortunately John T. Lyle's long term researches on environmental and sustainable design and in particular, his idea Regenerative Design sets powerful expression of a more adaptive ecological approach." [7]

Lyle believes that "If we accept that the current level of ecological consciousness is part of the beginning of a long-lasting, fundamental change in attitudes and environmental values, then landscape architecture must bear a large measure of responsibility for making aesthetic sense out of this attitudinal metamorphosis". [ 8]

As a landscape architect and specialist designer of desert climate, John C. Krieg[ 9] regarding ecology-oriented landscaping and considering ecological characteristics, some of important factors of his idea about desert design techniques are: Speak the local vernacular, Theme Gardens Evoke Emotions, Apply the unusual, Maximize views, Introduce water, and Invite wildlife. 


\section{Strategies and sources for Environmental Design and Eco-Park}

In this section, findings for Beshghardash Eco-Park, for example could define with the factors of both recent researches and findings: Lyle's Regenerative Design [10]and Taghvaei's "Oasis paradigm" proposal (2002) and "Ecologist Landscape Design" theory(2005).

First, for creating ecologically inspired landscape that is to contain the characteristics of spontaneous landscape, Lyle suggests observation of the following seven points: Working with nature, Enrichment through complexity, the landscape as process, Creativity on site, Involvement of the users, Minimal energy consumption, the natural landscape outside the front door.

Second, the properties inherent in the Oasis Paradigm defined systematically, through a field survey of Iranian desert landscape architecture, ecological tacit knowledge and supported by a literature review of Iranian historical texts on literature, religion, philosophy, agriculture, horticulture, and sciences. In addition, the main output and principle of the "Ecologist Landscape Design" follows a set of strategies for qualitative improvement in the landscape design of Hot Arid Zones (Specially in Iranian plateau). This entails a theoretical framework that can be refined by further research. They include: [11]

- Strategies for designing a sustainable habitable microclimate (oasis) interconnected to a bigger harsh macroclimate (desert/ Kavir)

- Patterns for physical planning of the built and planted environment;

- A theoretical framework for sitting, locating and expansion of existing landscapes; and

- The application of the theoretical framework to solve contemporary design problems such as cultural identity, energy conservation, preservation of natural resources and etc.

Finally, Symison [12]with a complete environmental view has simply introduced stability principles: 1) minimizing natural sources consumption, 2) All the wastes recycling or reuse, 3) Non- production of any pollution that is not recyclable or digestible, and 4) General rely on clean and renewable energy technologies. Indeed, the mentioned principles, after propounded sustainability are the basis of environmental design factors in Eco-Parks. Today by considering the discussed theories in environmental design and formation of a sustainable and ecologic landscaping specially in hot and semi-arid climate, and Golany's principle for planning in hot arid zones [13], we can refer to the following views in brief:

In conclusion to the above mentioned theories, "if we want the efficiency and sustainability of environment and landscape, the environmental designing decisions should be combined with nature's complex order and join the human and natural systems." [14]

\section{Environmental Design patterns for an Eco-Park}

In this part of essay 2 case studies have been examined and analyzed in details so that their thought patterns can be applied in organizing Beshqardash project.

Table 1: La mesa Eco-park[15]

\begin{tabular}{|c|c|}
\hline \multicolumn{2}{|c|}{ La mesa ; Philippines Kozen City; 2005} \\
\hline $\begin{array}{l}\text { Design } \\
\text { objectives }\end{array}$ & $\begin{array}{l}\text { Reconstruction \& Restoration Of } \\
\text { La mesa Dam and helping } \\
\text { environment sustainability }\end{array}$ \\
\hline $\begin{array}{l}\text { Physical } \\
\text { program }\end{array}$ & $\begin{array}{l}\text {-Design jungles in large scale to } \\
\text { restore vegetation of the area } \\
\text { - sport sections including walking } \\
\text { and bicycle riding paths, pools and } \\
\text { lakes for water sports as well as } \\
\text { fishing and boat riding } \\
\text { - cultural sections like wedding } \\
\text { and party reception halls and } \\
\text { amphitheater saloons } \\
\text { - Children and adults resting and } \\
\text { recreation section including places } \\
\text { suitable for picnic and playground } \\
\text {-educational and recreational } \\
\text { section including botany Gardens }\end{array}$ \\
\hline $\begin{array}{l}\text { important } \\
\text { points }\end{array}$ & $\begin{array}{l}\text {-By restoration of La mesa } \\
\text { abandoned zone and jungle making } \\
\text { plan in large scale, the area has been } \\
\text { converted to a natural educational } \\
\text { and recreational shelter } \\
\text {-The plan of restoration of the } \\
\text { destroyed environmental areas is a } \\
\text { key step in establishment of a } \\
\text { sustainable development. }\end{array}$ \\
\hline
\end{tabular}




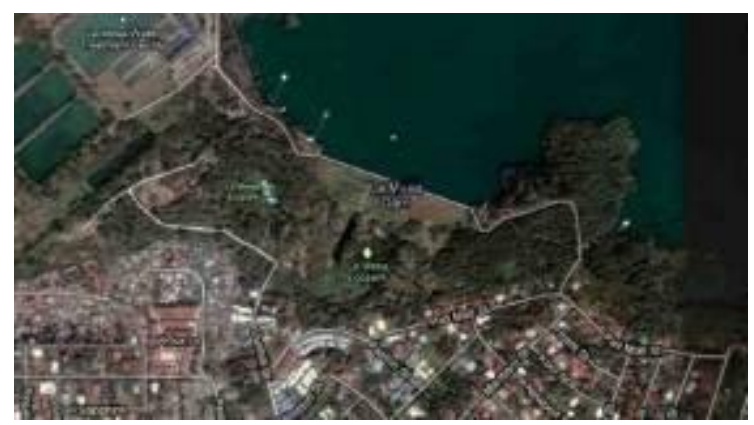

Figur2 2:Aerial view of Lamsa Eco-Park. (http://www.clickthecity.com/travel/)

Table 2: Birmingham Eco-park, [16]

\section{Birmingham Eco park; United state of America; 1997}

\begin{tabular}{|c|c|}
\hline $\begin{array}{l}\text { Design } \\
\text { objectives }\end{array}$ & $\begin{array}{l}\text {-The relation of schools student with } \\
\text { nature } \\
\text {-Making natural environments which } \\
\text { have stimulating educational role, } \\
\text { through designing woodlands, } \\
\text { canebrakes, lakes, lawns, and green } \\
\text { wooden shelters } \\
\text {-Applying solar energy, wind turbine } \\
\text { and polluted water recycling system }\end{array}$ \\
\hline $\begin{array}{l}\text { Physical } \\
\text { program }\end{array}$ & $\begin{array}{l}\text {-Educational recreational } \\
\text { environments for school students and } \\
\text { making a close relation with nature } \\
\text { through observing plant growth, hunting } \\
\text { animals } \\
\text {-Exhibiting spaces: } \\
\text { Innovative and varied landscape of } \\
\text { natural gardens, cane brakes and } \\
\text { displaying technologies related to } \\
\text { renewable resources } \\
\text {-Environments related to natural } \\
\text { ecosystem and protection of resources } \\
\text {-rain water collecting and leading it } \\
\text { into the lake and applying the excess } \\
\text { water for irrigation }\end{array}$ \\
\hline $\begin{array}{l}\text { The } \\
\text { important } \\
\text { points }\end{array}$ & $\begin{array}{l}\text {-Environment training for students } \\
\text { and teachers and increasing their } \\
\text { environmental knowledge } \\
\text {-Protection against water resources } \\
\text { available in the park } \\
\text { Usage of renewable resources and } \\
\text { material recycling }\end{array}$ \\
\hline
\end{tabular}

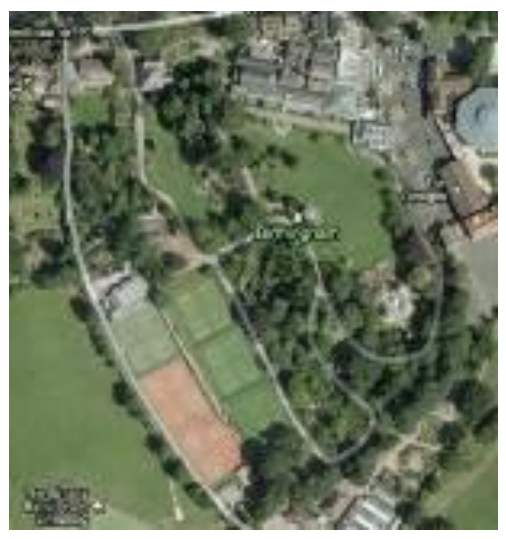

Figur3 3:Aerial view of Birmingham Eco-park (http://www.wild-net.org/wildbbc/)

\section{Design objectives}

According to what mentioned earlier, Ecopark objectives for designing Beshqardash will be summarized to the following principles that can ascertain objectives of sustainable development through provision of various aspects of sustainability.

\subsection{Protection of environment}

Protection of environment involves issues such as species variants, water resources protection, land resources protection, providing natural environment and land topology consistency with the project design.

\subsubsection{Planting indigenous species}

Vast representation of land natural ecosystem is a major feature of Eco-park. Thus, it is tried to retain regional landscape as possible by planting various indigenous plants (such as Alhagi Camelorom, Peganum harmala, Artemisia, Astrahalus, Salsola, Gramineas, Amygdalus Lycioides,...). Indigenous plants improve the regional climate and retain water resources effectively because these plants are compatible with the arid climate and compost retain more water and reduce vaporization. 


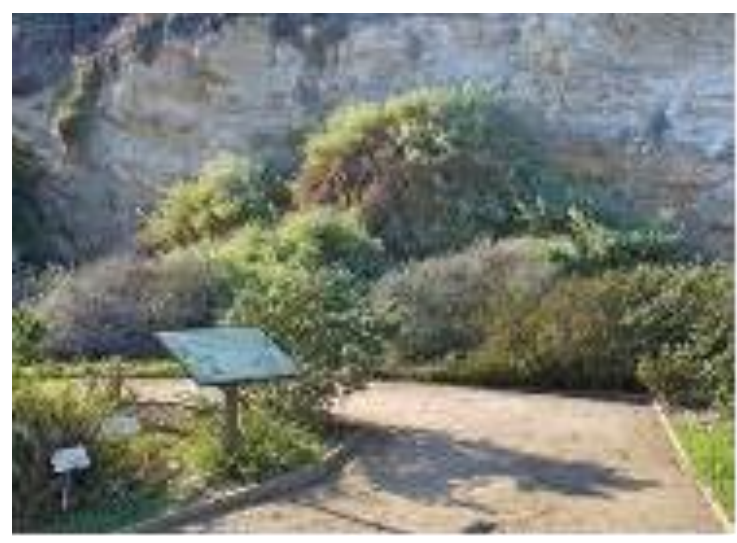

Figur4 4:Species diversity and use of native species. Personal Author's collection

\subsubsection{Forest project in the region water shed}

this project retain soil natural environment by planting proper species including broad-leaved as well as needle -leaved plants step wise 10 percent from total 340 hectares is allocated to pedestrian crossing, parking, sport area and arbors ; 300 hectares will be planted in watershed area forest cultivation in watershed area. Also the significant benefits which follow the forest making plant in this area should be taken into consideration that finally causes health of body, soul and environment.

\subsubsection{Water resource protection}

"Beshghardash main sprigs are located in its east watershed area and its protection is critical. However, the springs can't meet to provide the complex water requirements sufficiently and nearby water wells and springs as well as the river which is located in the lower west part of the complex must be exploited to fill the artificial lake and provide other water requirements. The water from the main springs is used uniquely for drinking because of its medical properties. On the whole, the sewage system should be guided out of the park properly in order not to pollute the under ground water. Water pumps are prohibited in this region otherwise a disastrous damage to underground water resources will occur." [17]

\subsection{Environmental Development}

Environmental Development involves sustainable resources allocation such as

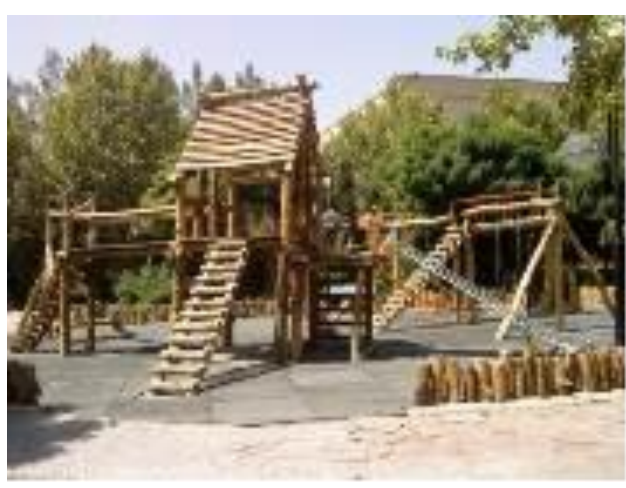

Figur5 5:Making use sustainable materials in Mashhad park. Personal Author's collection

providing water resources, sun and wind energies as well as sustainable materials.

\subsubsection{Making use sustainable materials}

Sustainable materials compromise a part of environment development in order to reduce the impact on human natural environment less legal and financial intended policies application has prevented the vast use of healthy materials. In addition, "design engineers have not paid enough attention to these materials, leading to basic technologic and knowledge loss in terms of proper using of the materials. Under these conditions, Eco-park provides suitable circumstances to access to new techniques of using sustainable materials." [18]

The relevant facilities in the Eco-park in terms of using sustainable materials include:

- Maximum use of ecologic materials with least impact on environment. For example, in Beshghardash region, local materials include rock and sun dried clay brick. In addition, the Eco-park wood production can be used in green building construction.

- Green restaurant can serve tourists with herbal and natural foods.

- "Recycling the materials and reusing them by replacing high risk materials with less harmful ones (less harmful materials are those with less natural concentration which impact less on ozone layer). Manures and composts are considered as sustainable materials and will ensure a sustainable recycle in the Eco-park." [18] 
6.2.2 Optimum use of water resources of the region

Natural spring water in Beshghardash can play a key rule in protecting the resistance of the region as one of the economical tool for this region. In this regard, apart from the consumption mentioned earlier spring water can be packed as mineral drinking water and be delivered to regional markets or exported to external markets. These activities will make people aware about the region and attract more people to travel to Bojnord and subsequently will produce additional income.

\subsubsection{The project of making use of healthy energies}

Remarkably waste materials of the Eco-park are recycled and energy is produced from renewable resources such as sun and wind energies which will lead to fossil fuels reduction. Sun-based energy can be used for lighting purposes or as sun energy-based ovens can be made available in the Eco-park for tourists. Using new systems of energy will make the Ecopark more attractive for tourists. This matter will also represent national maxim of self sufficiency. It would rather the wind turbine be installed on top of the hill, overlooking the Eco-park complex and its energy can be used for lighting purpose to exhibit all around the main springs area.

\subsection{Satisfying human needs and recreation in environment}

This involves generation equality, public preference, recreational and entertainment facilities. In addition; visitor will be familiar with environmental issues and terminology.

\subsubsection{Teaching environment issues}

"Birmingham Eco-park represents a good example for environment issues training representation along with recreation and entertainment. Various training sessions from few hours to whole a day are offered to students. Teachers are also trained with environment sciences. Birmingham training programs include following: plant growth exhibition, Understanding nature, Hunting small animals, and Environment-based arts and skills." [16]
The above activities are compatible with natural condition and facilities of the Eco-park similar activities can be devised, to train students while they are recreating. Such as fishing, walking and exploration through hills and slopes, rock- climbing, skiing on snow.

\subsubsection{Exhibition of environment}

Exhibition of environment issues such as water, energy, solutions will be performed simultaneously for two purposes: recreation as well as increasing public awareness. The exhibition can offer following in order to increase Eco-park beauty and attraction: natural orchard representation, Greenhouse, Sun-based and wind-based energies, and Natural springs and cultural heritage in the region.

\subsubsection{Financial resources}

It is intended that the Eco-park would be self sufficient in terms of financial resources by means of earning money through many offerings such as teaching facilities, exhibition the environment, green restaurants. These activities will lead to higher regional economical quality because it offers its services beyond the region itself. Following activities serve the same purpose: agricultural production direct supply, fishery facilities and direct offer of fish production to the visitor or permitting people to catch fish themselves.

\subsection{Compatibility with the conditions}

"Local, historical, cultural and other regional features are emphasized. Historical aspect of Beshghardash Park is unbelievably tied with historical background of these people and it seems that spending free time

and seeking shelter here in hot days of summer, has been a long tradition for the natives." [17]

\subsubsection{Emphasis on local attractions}

The natural spring in this Eco-park originates from Beshghardash nearby foothill, and is considered the most outstanding feature of the 
Table 3. A Pattern of Eco-park Design. produced by Authors

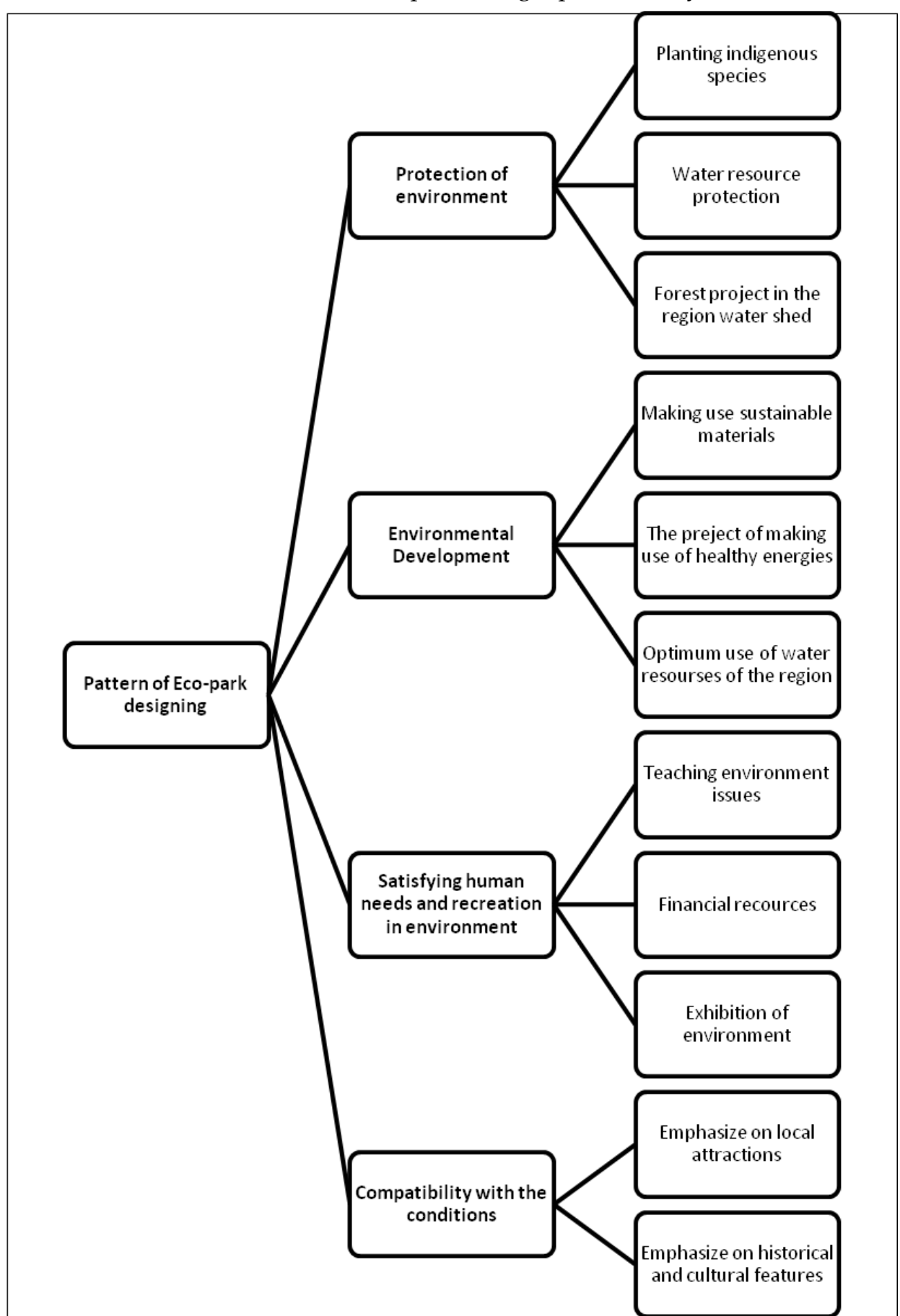

Eco-park project. The artificial lake has used as a water source for irrigation directly from the stream network all around the Eco-park. Rocky hills on the eastern side of the park attracts the people who are fond of running into the hills, watching beautiful visions and feeling a mild, encouraging and pleasant cold wind blowing lightly everywhere over the hills.

\subsubsection{Emphasis on historical and cultural features}

Local people still remember when they collectively recreated over the rocky slope on top of the spring or they swam inside the nearby pool in all seasons as well as many other memorable activities such as winter games over snowy slopes ,hunting partridge , holding traditional wrestling competition (Chookhe) in proper times throughout year, running on original "Turkman" Horseback through Beshghardash hills, the family traditional recreation in nature on a holiday with cooking so called Kabab by men, using wood and coal. Semi 
destroyed gate of the old orchard shows green environment all around the spring.

The historical building nearby the spring (Tomb) illustrates local traditional architecture. On the whole, by restoring the above mentioned traditions and customs one can intensify past memories and enhance identity by richness and personalization in spaces.

\section{Conclusion}

In Eco-park environment, all resources contribute and are closely connected to each other (such as environment data, native materials, green energies, infrastructures, ecologies). In results Eco-parks are capable to develop Complex activities. In other word, interaction and coordination among all activities in the park bring about the major goal; the Ecopark is intended to [19]In fact, the thing that makes an Eco-park successfully, is moving all activities in the park towards one single direction.

Beshghardash complex is considered one of tourist attractions in North Khorasan region (Iran) which represents many capabilities of recreation and entertainment. Study on the established Eco-parks in other countries show that the objectives for Eco-parks are achieved with lower expenses because of higher natural capabilities and suitable conditions in the relevant environment.

Therefore, it is tried to devise the least critical principles and it is illustrated objectively and concretely in the complex. In addition, by considering cultural and historical characteristics of the area especially religious groups in Iran's Islamic society (holding public prayer in Urban Spaces) we can achieve the special and suitable designing of Eco-park in the area. Finally, for applying the outcome of this paper in related complex and similar areas, the achieved principles and its application have been presented in the form of a diagram at the end of this essay (Figure 7). Its' practical realization can take basic steps in accessing Eco-parks (Figure 8). Once more it should be emphasized that considering the special cultural characteristics of any society is a must in achieving sustainable development.
Thus, when we treat architecture and landscape architecture just analytically, we miss the concrete environmental- ecological character, that is, the very quality which is the object of man's identification, and which may give him a sense of existential foothold. As Norberg-Shulz hermeneutics" "The man cannot gain a foothold through scientific understanding alone. He needs symbols, that is, works of art which represent life-situation." [20]

In addition, an important factor linking natural and human oriented sciences in landscape research is the mutual relationship between man and the landscape, between people's scientific and tacit knowledge and deep ecology; It is important point that people and social groups not only influence landscapes, but are also influenced by landscapes.

Therefore, with holistic treat and thought, beliefs support the conception of man and natural elements as being close together and forming a union. This conception of the relationship of man and nature elevates thought and culture necessary for survival in today's situation and the specials like harsh climate and arid zones in particular.

\section{References}

[1] Fuller , R.B (1975). Synergetics: Exploration in the Geometry of Thinking. Macmillan Books: New York, N.Y.

[2] Olkowski, H (1979). The integral urban house: Self-reliant living in the city. Sierra Club Books: SanFrancisco, Calif.

[3] Todd, N.J, and Todd, J (1994) . From eco-cities to living machines: Principles ofecological design. North Atlantic Books: Berkeley, Calif.

[4] Scott, F.A (1999 ) . Ecological design handbook: Sustainable strategies for architecture, landscape architecture.

[5] Mikaeili, A.R (2007). An overview of Eco-park design requirements (Persian). Third symposium of national green space and landscape conference, (pp. 115-130)

[6] Ben, jonson (1995). Environmental Ethics, In vahabzadeh, A.H(2003), Iran

[7]Taghvaei, S.Hassan (2008),Tacit Knowledge and Deep Ecology, Environmenta Science Magazin, Vol.6/No.1, Iran

[8] Lyle, John Tillman, (1996), Archetypes in the Arid Landscape, William Reilly (ed). Geneva: Aga Khan Trust for Culture.

[9] Krieg, John C. (1999), Desert Landscape Architecture, CRC. 
[10] Lyle, JohnTillman, (1984), Regenerative Design for Sustainable Development,

Wiley

[11] Taghvaei, S.Hassan (2005), Ph.D Thesis titled: "Ecologist Landscape Design in Hot Aid Zone of Iran: Oasis Paradigm", Beheshti University, Iran

[12]Simpson, W. (n.d.), What is sustainability? (A reflection on seven generation and beyond ), RetrievedDec20, 2005. From http://www.tufts.edu/tie/tci/pdf/What\%20.pdf

[13]Golany, Gideon, Desert Planning, NI.publishing, 1982

[14]John L. Motloch (2000). Introduction to Landscape design, Parks and green $\mathrm{s}$ pace organization in Tehran

[15]Donna Corpin (2006). La Mesa Eco Park: Paradise found, Retrieved From (http://www.clickthecity.com/travel/)

[16] Guy Belding (2010). Wildlife Trust for Birmingham and the Black Country, Protecting Wildlife For The Future, (http://www.wild-net.org/wildbbc/)

[17]Part consulting engineering (2006). Beshghardash development project. Bojnord,

[18]Nina Nakajima (2000).A Vision of Industrial Ecology: State-of-the-Art Practices for a Circular and Service-Based Economy, Bulletin of Science Technology Society; 20,

[19]Fan Shu-Yang, Bill Freedman, \& Raymond Cote (2004). principles and practice of ecological design, The NRC Research.(http:// www.er.nrc.ca/)

[20]Norberg-Shulz,C.(1984), The Concept of Dwelling: On the Way to Figurative Architecture. New York, Rizzoli International Publications 
Table 3. A Pattern of Eco-park Design. produced by Authors

\section{Acknowledgment}

Agradecimentos a revisores, colaboradores e agências de fomento.

\section{References}

Akaike, H. (1973). Information theory and an extension of the maximum likelihood principle. Em: Proceedings of the 2nd International Symposium on Information Theory, pp. 267-281.

Ferrari, S. L. P., Cribari-Neto, F. (2004). Beta regression for modelling rates and proportions. Journal of Applied Statistics, 31(7), 799-815.

McCullagh, P., Nelder, J. (1989). Generalized linear models, 2o edn. Chapman and Hall.

R Development Core Team (2009). R: A language and environment for statistical computing. $R$ Foundation for Statistical Computing, Vienna, Austria, URL 